\title{
Cerebral Venous Thrombosis with Subarachnoid Hemorrhage: a Case Report
}

\author{
José Carlos Arévalo-Lorido, MD and Juana Carretero-Gómez, MD
}

\begin{abstract}
Cerebral venous thrombosis (CVT) presenting as subarachnoid hemorrhage (SAH) is infrequent. We present the case of a man with CVT of the right transverse sinus who presented with a SAH in the right parietal sinus. In this case, we describe a hyper-homocysteinemia in a heterozygous patient for the methylenetetrahydrofolate reductase C667T mutation. Our report highlights the value of an early diagnosis of CVT, the importance of identifying possible causes that could be reversed with an appropriate treatment, and the controversy about the timing for starting anticoagulation therapy in such cases.
\end{abstract}

Keywords: Cerebral venous thrombosis, Cortical subarachnoid hemorrhage, Homocysteine

Corresponding Author:

José Carlos Arévalo-Lorido, MD

Hospital de Zafra

Ctra Badajoz Granada $s / n$

06300 Zafra, Badajoz SPAIN

Email: joscarlor@gmail.com

Received: January 27, 2014

Revised: April 2, 2014

Accepted: April 21, 2014

doi: $10.3121 / \mathrm{cmr} .2014 .1225$
$\mathrm{C}$

erebral venous thrombosis (CVT) is a disease seen in increasing frequency in daily practice and has a variety of nonspecific clinical symptoms that are shared with other disorders. It most frequently presents with an acute onset of headache, increasing in the severity of intensity in up to $77 \%$ in some studies. ${ }^{1}$ However, CVT presenting with an associated subarachnoid hemorrhage (SAH) on computed tomography (CT) and magnetic resonance imaging (MRI) is infrequent. ${ }^{2,3} \mathrm{SAH}$ is becoming more frequently recognized as a potential complication of CVT.

High levels of homocysteine are a known risk factor for venous and arterial thrombosis. However, its role in stroke remains controversial, and a positive association between homocysteine and stroke has not been established in some nested case-control studies. ${ }^{4}$

We present the case of a patient with thrombosis in the right transverse sinus with associated SAH. We describe the imaging and laboratory findings regarding high levels of homocysteine as a potential etiology in this case. Finally, we discuss the treatment chosen and the management of CVT with SAH.

\section{Case Report}

A man, aged 70 years, with progressive occipital headache and nausea was admitted to our ward. He had a clinical history of hypertension that was being treated with ramipril $5 \mathrm{mg}$ per day. The rest of his past medical history was unremarkable. On admission, he was afebrile with a blood pressure of 140/70 $\mathrm{mmHg}$. Physical and neurological examinations were normal with no evidence of meningism or any focal neurological deficit. A CT scan was performed showing SAH in the right parietal lobe (figure 1). MRI confirmed this and, in addition, 


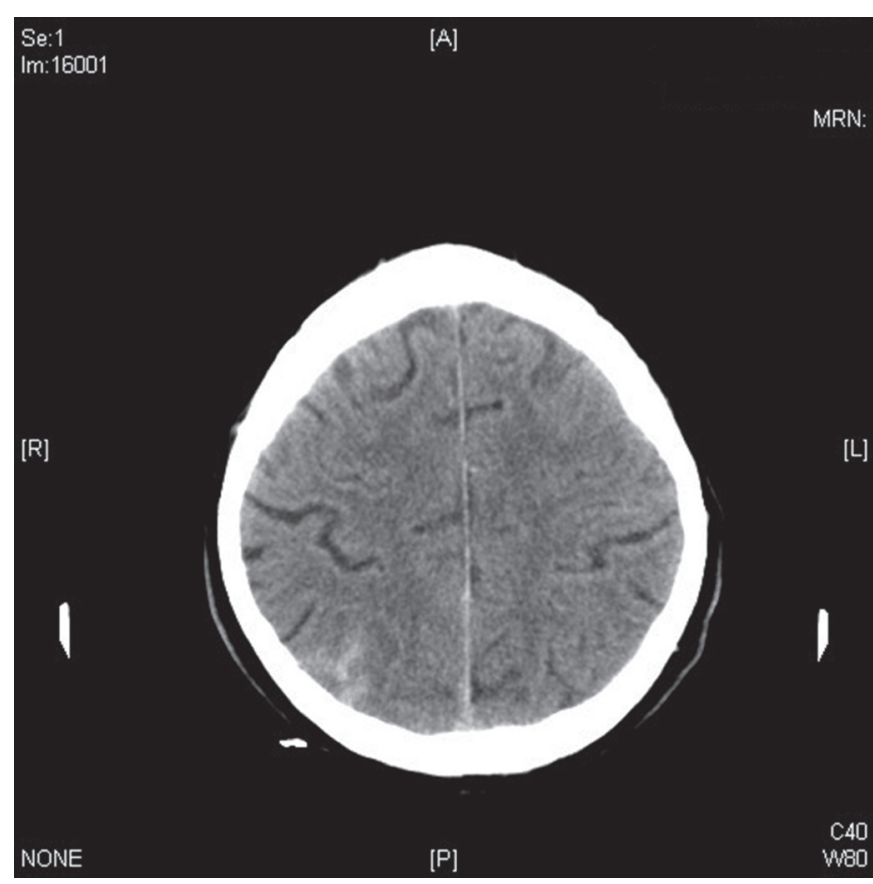

Figure 1. Computed tomography scan of the patient showing subarachnoid hemorrhage.

showed a thrombosis in the right transverse sinus (figures 2 and 3). The angiography revealed no aneurysm. The patient underwent a complete hemocoagulative study comprehensive of protein $\mathrm{C}$, protein $\mathrm{S}$, antithrombin III, homocysteine, antiphospholipid antibodies and lupus anticoagulant, resistance to activated protein $\mathrm{C}$, factors VIII and VII, mutation analysis of the prothrombin gene, and factor $\mathrm{V}$ Leiden. All results were in the normal range except for total homocysteine that was $26 \mu \mathrm{mol} / \mathrm{L}$ (normal value $<15$ $\mu \mathrm{mol} / \mathrm{L}$ ). The levels of folic acid and cobalamine were normal at $5.9 \mathrm{ng} / \mathrm{mL}$ (normal range $3-17 \mathrm{ng} / \mathrm{mL}$ ) and $169 \mathrm{pg} / \mathrm{mL}$ (normal range 211-911 pg/mL), respectively. We later found that the patient was heterozygous for the methylenetetrahydrofolate reductase C667T mutations.

We began treatment with ordinary care. Low-molecular weight heparin, $60 \mathrm{mg}$ once a day, was initiated from admission. The third day after admission, we raised the dose to $120 \mathrm{mg}$ per day for a week. The patient was then started oral anticoagulation after no evidence of worsening of SAH.

\section{Discussion}

CVT is responsible for $1 \%$ to $2 \%$ of all strokes in adults, ${ }^{5}$ but isolated CVT (without sinus involvement) appears very rare. Furthermore, CVT is a potential cause of cortical SAH. Panda et $\mathrm{al}^{6}$ reported that 10 of 233 patients with CVT had evidence of cortical SAH, and Oda et $\mathrm{al}^{7}$ found $3 \%$ of SAH was caused by CVT, indicating that the presence of cortical SAH without involvement of the basal cisterns may provide an early sign of underlying CVT. However, what is more interesting in this case, is the relationship of high levels of plasma homocysteine with CVT and SAH, previously undescribed.
There is broad epidemiological evidence to correlate elevated levels of homocysteine with increased risk of thromboembolic events; ${ }^{8,9}$ however, most studies have been case-control studies for which blood samples drawn to measure homocysteine were collected after the event. The methylenetetrahydrofolate reductase (MTHFR) gene polymorphism introduced another means of testing the hypothesis of causality between homocysteine levels and venous thrombosis; however, an association between MTHFR gene mutations and venous thrombosis has not been found by different studies. ${ }^{10,11}$ Regarding CVT, recent publications showed a relationship with increased levels of homocysteine but not with MTHFR gene mutations. ${ }^{12,13}$ The current hypothesis is that MTHFR gene mutations (both 677TT and 677CT) raise plasma levels of homocysteine that produce an increased risk for cardiovascular events and that the level of hyperhomocysteine to induce endothelial dysfunction in cerebral vessels is lower than the level needed to produce the same alteration in systemic circulation. ${ }^{14}$

The distribution of SAH associated with CVT is usually different from that of SAH of arterial origin, which has a characteristic pattern. In fact, when SAH is localized at the cerebral convexity and spares the basal cisterns and skull base, CVT should be considered. ${ }^{6}$

The exact mechanism of cortical SAH caused by CVT is unknown. One possibility is the rupture of venous parenchymal hemorrhagic infarcts into the subarachnoid space, ${ }^{15,16}$ although signs of hemorrhagic venous infarction were not found in our patient. Another possible mechanism is venous hypertension and subsequent rupture of dilated, valueless, thin-walled, bridging subarachnoid cortical veins devoid of smooth muscle fibers. ${ }^{15}$ This mechanism could be consistent with that

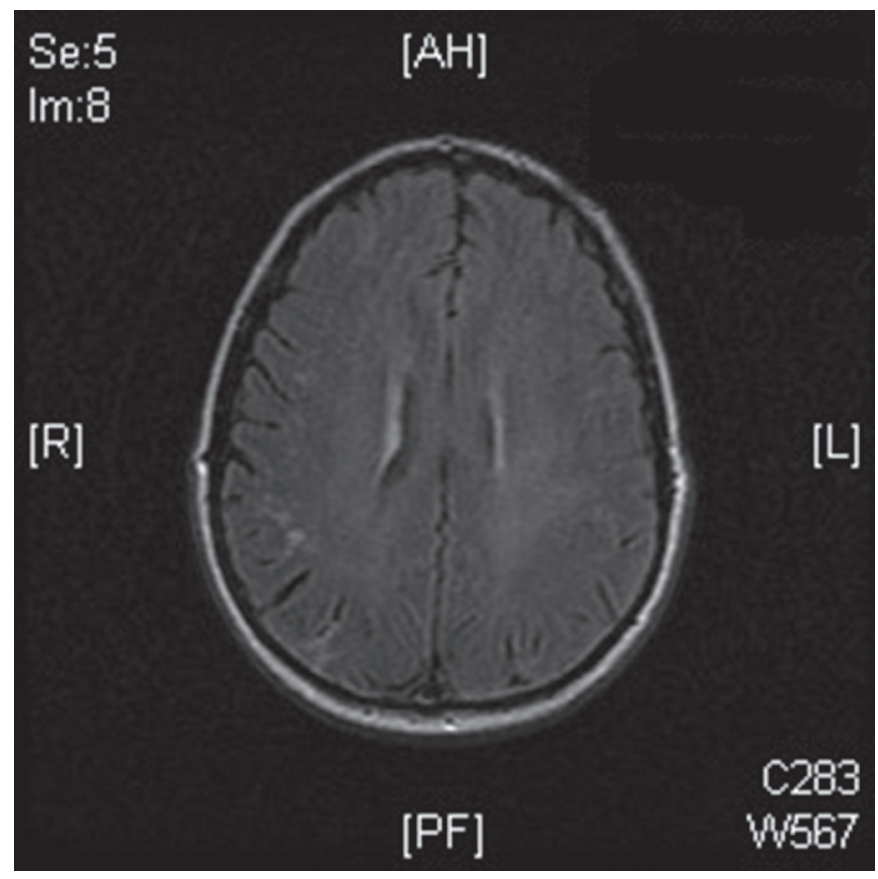

Figure 2: Magnetic resonance imaging of the patient showing subarachnoid hemorrhage in right parietal lobe. 


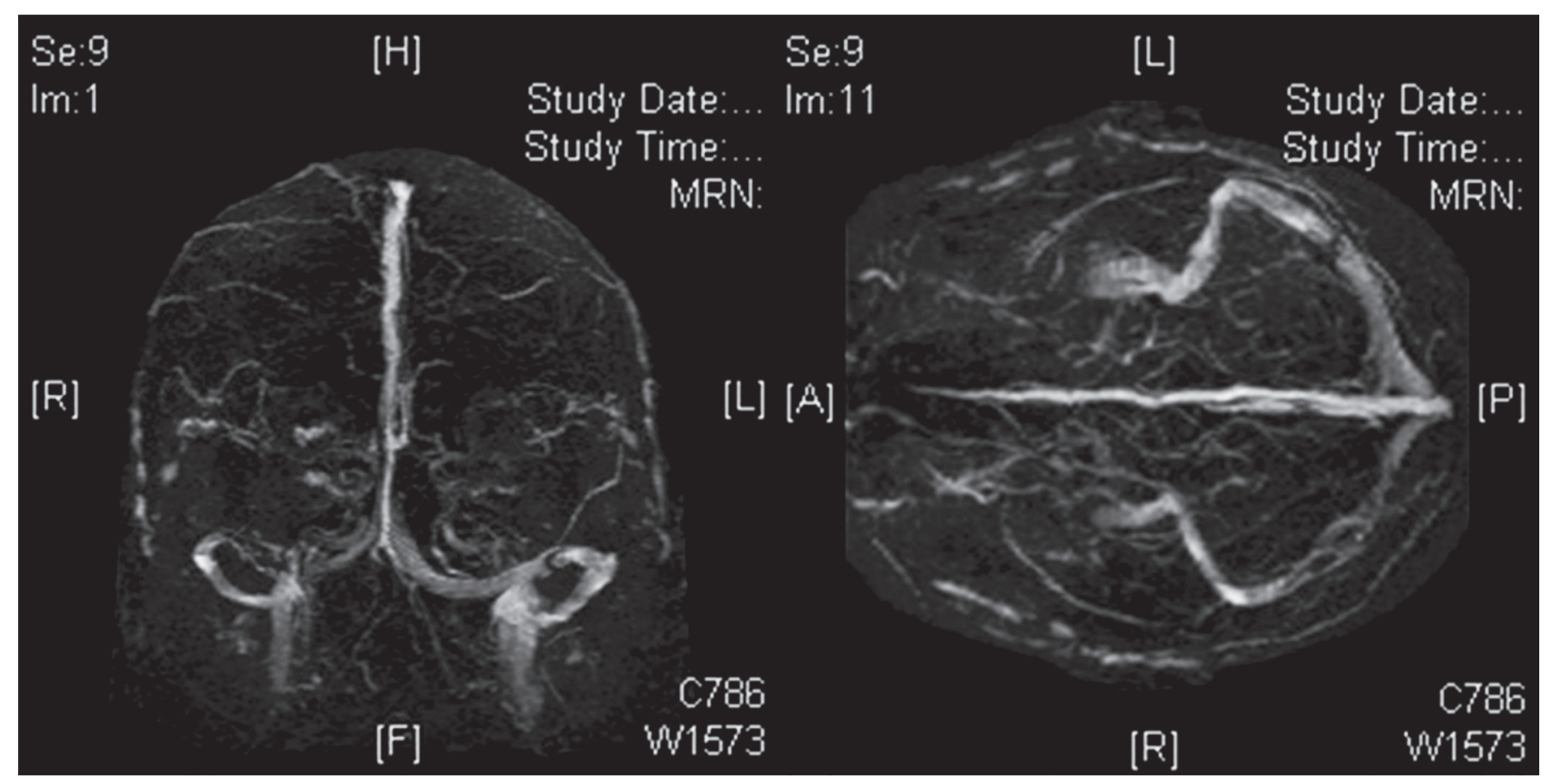

Figure 3: Angiography (venous phase) showing the thrombosis in the right transverse sinus.

of our patient, because in these cases, SAH usually occurs in the region adjacent to thrombosed veins or sinuses.

Finally a third mechanism of SAH development could be a local inflammatory response caused by CVT, which would increase the vascular permeability allowing for extravasation of blood into the subarachnoid space. This mechanism also could have been present in our patient, who had proinflammatory status because of his altered metabolism of homocysteine. In fact, hyperhomocysteinemia is thought to lead to endothelial dysfunction, probably produced by reduction in the availability of nitric oxide, ${ }^{17}$ and to an increase of the oxidative stress with alteration of the redox state of the endothelium. ${ }^{18}$

Management of SAH secondary to CVT is quite different from that of arterial SAH. The usual treatment of sinus thrombosis is anticoagulation or local thrombolysis. Systemic anticoagulation is the first line treatment for CVT because of its efficacy, safety, and feasibility. ${ }^{19}$ In a further placebocontrolled trial, 60 patients were randomized to either lower molecular weight heparin followed by warfarin or placebo. ${ }^{20}$ The anticoagulated patients had better outcomes than controls, but the difference was not statistically significant. The investigators suggested that anticoagulation was safe, even in patients with cerebral hemorrhage. ${ }^{19}$ However, the present case was not an intraparenchymal hemorrhage, but SAH. We considered that intravenous heparin would deteriorate $\mathrm{SAH}$ and preferred to initiate low doses of fractionated heparin, 60 mg once a day. Then, on the third day, we raised doses to 120 mg per day for a week. On the second week, oral anticoagulation was started after no evidence of worsening of SAH. Anticoagulation had not been started so early in other cases reported, ${ }^{7}$ because of the high risk of bleeding; although in the present case, knowing that SAH was secondary to CVT, anticoagulation achieved an excellent recovery in the patient.

\section{Conclusion}

CVT should be considered in the differential diagnosis of patients presenting with SAH without evidence of aneurysm. When diagnosed, we must take into account a well-defined study of thrombophilia and procoagulative pathways to identify all possible causes that could be reversed with an appropriate treatment, as in the case of hyperhomocysteinemia. We emphasize that anticoagulant therapy should be started as soon as possible, depending on stability of the bleeding.

\section{References}

1. Iurlaro S, Beghi E, Massetto N, Guccione A, Autunno M, Colombo B, Di Monda T, Gionco M, Cortelli P, Perini F, D'Onofrio F, Agostoni E. Does headache represent a clinical marker in early diagnosis of cerebral venous thrombosis? A prospective multicentric study. Neurol Sci 2004;25:S298-S299.

2. Benabu Y, Mark L, Daniel S, Glikstein R. Cerebral venous thrombosis presenting with subarachnoid hemorrhage. Case report and review. Am J Emerg Med 2009;27:96-106.

3. Martelli N, Colli BO, Assirati Junior JA, Machado HR. Cerebromeningeal hemorrhage. Analysis of autopsies performed over a 10-year period. Arq Neuropsiquiatr 1998;46:166-175.

4. Verhoef P, Hennekens CH, Malinow MR, Kok FJ, Willet WC, Stampfer MJ. A prospective study of plasma homocyst(e)ine and risk of ischemic stroke. Stroke 1994;25:1924-1930.

5. Leach JL, Strub WM, Gaskill-Shipley MF. Cerebral venous thrombus signal intensity and susceptibility effects on gradient recalled-echo MR imaging. AJNR Am J Neuroradiol 2007;28:940-945. 
6. Panda S, Prashantha DK, Ravi Shankar S, Nagaraja D.

Localized convexity subarachnoid haemorrhage - a sign of early cerebral venous sinus thrombosis. Eur J Neurol 2010;17:1249-1258.

7. Oda S, Shimoda M, Hoshikawa K, Osada T, Yoshiyama M, Matsumae M. Cortical subarachnoid hemorrhage caused by cerebral venous thrombosis. Neurol Med Chir (Tokyo) 2011;51:30-36.

8. Hankey GJ, Eikelboom JW. Homocysteine and vascular disease. Lancet 1999;354: 407-413.

9. Kiltner SJ, Giles WH, Macko RF, Hebel JR, Wozniak MA, Witgk RJ, Stalley PD, Stern BJ, Sloan MA, Sherwin R, Price TR, McCarter RJ, Johnson CJ, Earley CJ, Buchholz DW, Malinow MR. Homocysteine and risk of cerebral infarction in a biracial population: the stroke prevention in young women study. Stroke 1999;30:1554-1560.

10. Wald DS, Law M, Morris JK. Homocysteine and cardiovascular disease: evidence on causality from a metaanalysis. BMJ 2002;325:1202-1209.

11. Naess JA, Christiansen SC, Romnudstad PR, Cannegieter SC, Blom HJ, Rosendaal FR, Hammerstrom J. Prospective study of homocysteine and MTHFR 677TT genotype and risk for venous thrombosis in a general population-results from the HUNT-2 study. Br J Haematol 2008;141:529-535.

12. Lauw MN, Barco S, Coutinho JM, Middeldorp S. Cerebral venous thrombosis and thrombophilia: a systematic review and meta-analysis. Semin Thromb Hemost 2013;39:913-927.

13. Bharatkumar VP, Nagaraja D, Christopher R. Hyperhomocysteinemia and methylenetetrahtdrofolate reductase $\mathrm{C677T}$ polymorphism in cerebral veno-sinus thrombosis. Clin Appl Thromb Hemost 2014;20:78-83.

14. Lentz SR, Dayal S, Aming E, Bottiglieri T, Sigmund CD, Faraci FM. Role of superoxide in cerebrovascular dysfunction in hyperhomocysteinemia in mice. Circulation 2002;106: II-III. Abstract.

15. Cuvinciuc V, Viguier A, Calviere L, Raposo N, Larrue V, Cognard C, Bonneville F. Isolated acute nontraumatic cortical subarachnoid hemorrhage. Am J Neuroradiol 2010; 31: $1355-1362$

16. Kato Y, Takeda H, Furuya D, Nagoya H, Deguchi I, Fukuoka T, Tanahashi N. Subarachnoid hemorrhage as the initial presentation of cerebral venous thrombosis. Intern Med 2010;49:467-70

17. Mayo JN, Beard RS Jr, Price TO, Chen CH, Erickson MA, Ercal N, Banks WA, et al. Nitrative stress in cerebral endothelium is mediated by mGluR5 in hyperhomocystinemia. J Cereb Blood Flow Metab 2012; 32(5): 825-834.

18. Yang TH, Chang CY, Hu ML. Various forms of homocysteine and oxidative status in the plasma of ischemic stroke patients as compared to healthy controls. Clin Biochem 2004; 37(6): 494-499.

19. Rodallec MH, Krainik A, Feydy A, Helias A, Colombani JM, Julles MC, et al. Cerebral venous thrombosis and multidetector CT angiography: tips antd tricks. Radiographics 2006; 26: S5-S18.

20. de Bruijn SF, Stam J. Randomized, placebo-controlled trial of anticoagulant treatment with low-molecular-weight heparin for cerebral sinus thrombosis. Stroke 1999; 30: 484-488.

\section{Author Affiliations}

José Carlos Arévalo-Lorido, MD*;

Juana Carretero-Gómez, MD*

*Internal Medicine Department, Zafra Hospital, County

Badajoz, Spain. 